\title{
Cuticular Wax Composition of Coconut Palms and their Susceptibility to Lethal Yellowing Disease
}

\author{
Gabriela A. Arroyo-Serralta, ${ }^{1}$ Daniel Zizumbo-Villareal, ${ }^{2}$ Fabiola Escalante Erosa, ${ }^{1}$ and Luis M. Peña- \\ Rodríguez $^{1 *}$ \\ ${ }^{1}$ Laboratorio de Química Orgánica, Unidad de Biotecnología, Centro de Investigación Científica de Yucatán, Calle 43, No. \\ 130, Col. Chuburná de Hidalgo, Mérida, Yucatán, México, 97200. Tel. +52 (999) 981-3923; Fax. (999) 981-3900. \\ lmanuel@cicy.mx \\ ${ }^{2}$ Unidad de Recursos Naturales, Centro de Investigación Científica de Yucatán, Mérida, Yucatán, México 97200
}

Dedicated to Dr. Estela Sánchez de Jiménez for her invaluable contributions to plant biochemistry

Received March 11, 2011; accepted August 9, 2011

\begin{abstract}
A number of metabolites isolated and identified from cuticular waxes have been used as chemotaxonomical markers and to explain the role of the wax layer in plant-insect and plant-pathogen interactions. Chromatographic analysis of the cuticular wax from pinnae of five coconut palm ecotypes showed that the three main components (I, II, III) in the wax can be used as chemotaxonomical markers for classification. The positive correlation found between the content of metabolites I, II, and III in the wax from the various ecotypes and their resistance or susceptibility to the lethal yellowing disease of coconut palms, did not coincide with the results obtained in an antifeedant assay. The results suggest that while the individual components do not play a significant role in the palm-insect interaction, the full composition of the cuticular wax does.
\end{abstract}

Key words: Skimmiwallin, isoskimmiwallin, lupeol methylether, $\mathrm{Co}$ cos nucifera, cuticular wax, pinnae, cycloartenols.

\section{Introduction}

The coconut palm (Cocos nucifera $\mathrm{L}$.) is cultivated in more than a hundred countries around the world, covering a surface of approximately twelve million hectares and producing ten million metric tons of copra. Mexico, with approximately 160,000 hectares, is the first copra producer in Latin America and the seventh one in the world $[1,2]$.

One of the factors that seriously affects the production of copra in many parts of the world, particularly in Central America, the Caribbean and Africa, is the lethal yellowing disease (LYD) of coconut palms; this disease is believed to be caused by a phytoplasm which is transmitted by at least one homopterous insect of the Cixiidae family, Myndus crudus Van Duzee [3].

Palms with LYD generally die within months of being infected. Although a number of strategies have been attempted to contain the destructive effects of the disease, including the use of insecticides to control the vector and of antibiotics to eliminate the phytoplasm, to date, replanting the affected zones with resistant varieties of coconut palms appears to be the best option [4].

A comprehensive evaluation which included morphological, physiological and isoenzymatic studies of the 18 major populations of $C$. nucifera growing in different regions of Mexico, allowed recognition of five ecotypes or groups of
Resumen. Un número de metabolitos aislados e identificados de ceras epicuticulares se han utilizado como marcadores quimiotaxonómicos y para explicar el papel de las ceras en las interacciones planta-insecto y planta patógeno. El análisis cromatográfico de la cera epicuticular de las pinas de cinco ecotipos de cocotero mostró que los tres componentes principales (I, II, III) en la cera se pueden utilizar como marcadores quimiotaxonómicos de clasificación. La correlación positiva entre el contenido de los metabolitos I, II y III en la cera de los diferentes ecotipos y su resistencia o susceptibilidad a la enfermedad del amarillamiento letal en palmas de cocotero, no coincidió con los resultados obtenidos en un bioensayo de actividad antialimentaria. Los resultados sugieren que mientras los componentes puros no juegan un papel importante en la interacción palma-insecto, la composición total de la cera epicuticular si lo hace.

Palabras clave: Eskimiwalina, isoskimiwalina, lupeolmetiléster, $\mathrm{Co}$ cos nucifera, cera epicuticular, pinas, cicloartenoles.

coconut palms considered to be phenotypically different. These ecotypes have been registered, following international nomenclature, as Mexican Atlantic Tall (MXAT), Malayan Yellow Dwarf (MYD), Mexican Pacific Tall 1 (MXPT1), Mexican Pacific Tall 2 (MXPT2), and Mexican Pacific Tall 3 (MXPT3) $[5,6]$.

When maintained under similar conditions, coconut palms of the five ecotypes described above showed a differential response against LYD, with MXAT and MYD individuals showing the most and least susceptibility to the disease, respectively. Of the remaining ecotypes, MXPT2 showed the second-highest resistance to LYD, followed by MXPT1 and MXPT3 [6, 7].

In some higher plants, morphological and chemical studies carried out on cuticular waxes have been used both as a chemotaxonomic marker for classification and to correlate the nature and the chemical composition of the wax, with the susceptibility of the plant to insect attack or to chemical agents [8-23].

Studies carried out on the chemical composition of the cuticular waxes from various palm species have resulted in the isolation and identification of a number of triterpenes, including lupeol methylether from Orbignya speciosa, Butia capitata and Orbignya phalerata, and cylindrin from Orbignya cohune [22]. Recently, the three main components of the cuticular wax of $C$. nucifera were identified as lupeol methylether (I) and the novel isomeric cycloartanes skimmiwallin (II) and isoskimmiwallin (III) (Fig. 2b) [24]. Here we wish to report on the variation in 


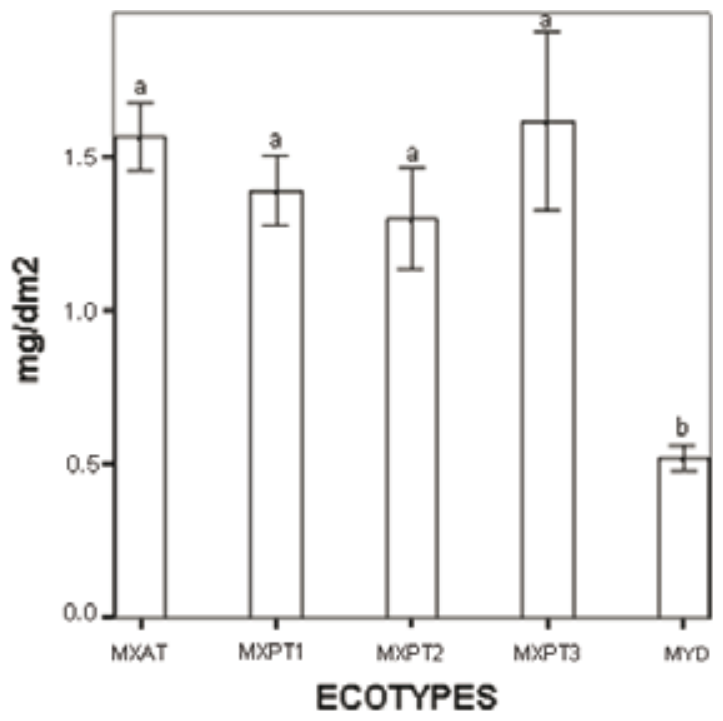

Fig. 1. Total wax content of Cocos nucifera ecotypes (number of individuals $=10$; values with similar letters are not significantly different. For mean and standard error see Table 1 in the Materials and Methods section).

total content and chemical composition of the cuticular wax of the five main ecotypes of $C$. nucifera growing in Mexico, together with the possible use of the chemical composition of the cuticular wax as a chemotaxonomical marker for classification, and the importance of the composition of the cuticular wax of a given palm ecotype in its resistance or susceptibility to LYD.

\section{Results and Discussion}

The results on the total yield of cuticular wax of the different ecotypes showed that palms belonging to the MYD ecotype had the lowest amount of wax (Fig. 1). This finding could explain the high susceptibility of the MYD ecotype to drought conditions, since previous reports have shown that cuticular wax content in drought-tolerant $C$. nucifera genotypes is usually higher than in those that are drought-susceptible [25]. At the same time, the low amount of cuticular wax in the MYD ecotype seriously challenges the argument that the resistance of MYD ecotypes to LYD is simply due to the cuticular wax acting as a physical barrier against insect attack. Statistical analyses of the total wax content of the different coconut palm ecotypes showed that while the total wax content in the MYD ecotype is clearly different to that of the remaining ecotypes, the differences between the four "tall " ecotypes are not statistically significant (Fig. 1).

The GC analyses of the different cuticular wax extracts showed chromatographic profiles that were qualitatively similar, but quantitatively different, i.e. they all contained the same three major components, namely lupeol methylether (I), skimmiwallin (II) and isoskimmiwallin (III), but in different proportions (Fig. 2a). A recent study has confirmed that I, II and III are the major components in all coconut palm wax extracts,

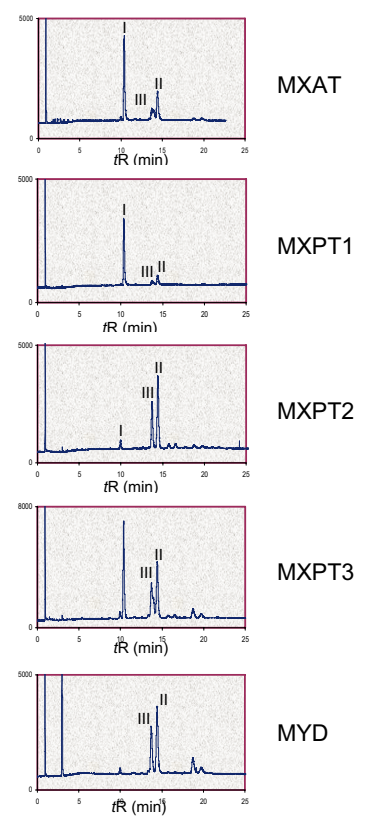

(a)

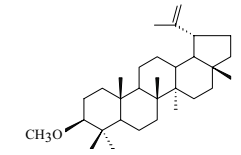

(I)

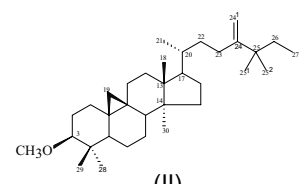

(II)

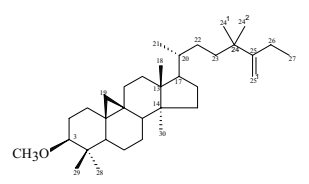

(III)

(b)

Fig. 2. (a) Chromatographic profiles of the epicuticular wax of $C$. nucifera ecotypes. (b) Major components of the epicuticular wax of C. nucifera [lupeol methyl ether (I), skimmiwallin (II) and isoskimmiwallin (III)]. Results based on the analyses of waxes from 10 individuals.

and that these three metabolites, together with minor amounts of lupane methyl-ether, lupeol and the acetylated derivatives of lupeol, isoskimmiwallinol and skimmiwallinol, represent $95 \%$ of the total wax content in all ecotypes; with the remaining $5 \%$ including non-identified triterpenoids, sterols, primary alcohols and fatty acids $[26,27]$.

The chromatographic profiles of the wax extracts showed that the similarities in the chemical composition of the cuticular wax of the five ecotypes, appeared to be in agreement with their degree of susceptibility or resistance to LYD, i.e. the chromatographic profile of the cuticular wax of the most susceptible MXAT ecotype was similar to those of the MXPT1 and MXPT3 ecotypes; while the chromatographic profile of the resistant MYD ecotype was similar to that of the second most-resistant MXPT2 ecotype (Fig. 2a). GC analyses of the cuticular wax extracts of each ecotype showed that while lupeol-methylether (I) is the most abundant component in the cuticular wax from both the MXAT and MXPT3 ecotypes, its presence in the wax of the LYD-resistant MYD ecotype is hardly noticeable (Fig. 3). Similarly, the content of skimmiwallin (II) and isoskimmiwallin (III) is considerably larger in the wax extracts of the MYD and MXPT2 ecotypes, when compared to that in similar extracts from LYD-susceptible MXAT, MXPT1 or MXPT3 ecotypes (Fig. 3).

A dendogram obtained through the analysis of hierarchical conglomerates showed five definite branches (Fig. 4); the presence of two main branches, one including the MYD ecotype 


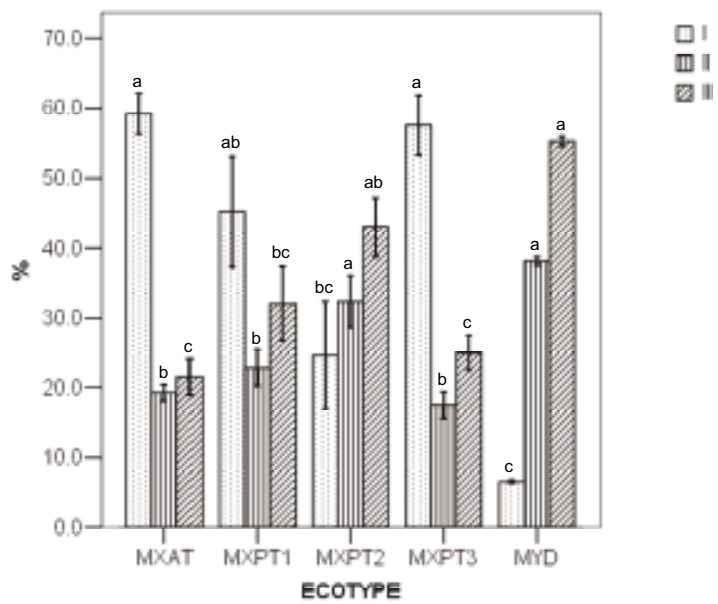

Fig. 3. Relative abundance of lupeol-methylether (I), skimmiwallin (II) and isoskimmiwallin (III) in epicuticular wax of Cocos nucifera ecotypes (number of individuals $=10$; values with similar letters are not significantly different; for mean and standard error see Table 1 in the Materials and Methods section).

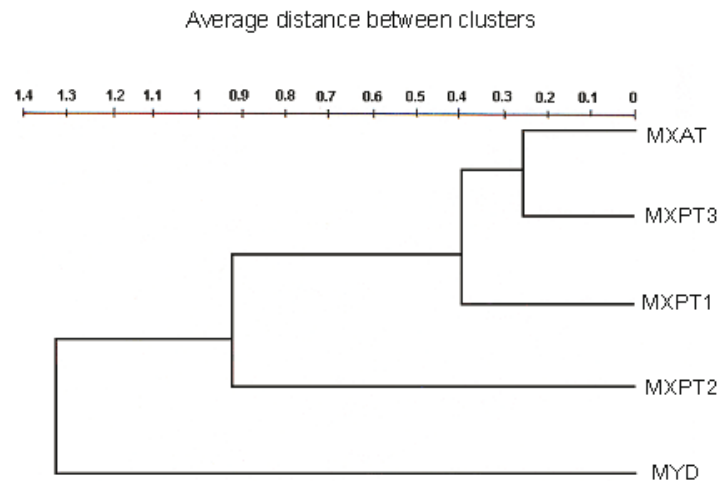

Fig. 4. Dendogram of the five ecotypes of Cocos nucifera growing in México. Average linkage cluster analysis based on epicuticular leaf wax components. MXAT $=$ Mexican Atlantic Tall, MYD $=$ Malayan Yellow Dwarf, MXPT1 = Mexican Pacific Tall 1, MXPT2 $=$ Mexican Pacific Tall 2, and MXPT3 = Mexican Pacific Tall 3.

and the other one the rest of the "tall" ecotypes, clearly indicated that the former is well differentiated from the rest. However, the presence of the MXPT2 ecotype in the first secondary branch confirms the close relationship between this ecotype and the MYD; at the same time, the close relationship between the MYD and MXPT2 ecotypes can explain their being the two most resistant ecotypes to LYD. Additionally, the location of the MXAT ecotype in the fifth branch clearly shows that this and MYD are the two most differentiated ecotypes. Again, these differences between the MXAT and MYD ecotypes correlate with their higher susceptibility and resistance to LYD, respectively. Finally, all of these results coincide with those reported earlier using both morphological, physiological, and molecular characters $[5,6]$, and confirm the importance of the amount and chemical composition of the cuticular waxes of C. nucifera ecotypes as chemotaxonomical markers for classification.
Taking into account that the amount and composition of cuticular waxes are important factors in plant-insect interactions [9, 11, 13-21, 23], and being that LYD is believed to be an insect-transmitted disease, the possible correlation between LYD susceptibility and both total wax content and abundance of components I, II and III in the cuticular wax from the five ecotypes was explored. This was done by using a simple regression analysis of the average values for each variable and the LYD-related mortality data for each ecotype $[6,7]$. The results showed that while the correlation between total wax content and LYD-related mortality was not significant (Fig. 5a; $P=$ 0.15 ), the correlation between the content of lupeol-methylether (I) and LYD-related mortality was positive and significant (Fig. $5 \mathrm{~b}, P=0.03$ ); this last result suggested that coconut palms having cuticular waxes with high concentrations of $\mathbf{I}$ are likely to have a higher susceptibility to LYD. Similarly, the negative correlation observed between LYD-related mortality and the concentration of skimmiwallin (II) and isoskimmiwallin (III) in the cuticular wax (Figs. $5 \mathrm{c}$ and $5 \mathrm{~d}, P=0.06$ and 0.02 ) suggests that ecotypes with cuticular waxes higher concentrations of metabolites II and III are more likely to resist LYD.

A recent evaluation of the antifeedant activity of the cuticular wax extracts of the five ecotypes, as well as of the purified metabolites I, II and III, showed that only the MYD wax extract has a significant antifeeding activity when tested against Diaphania hyalinata L. (Crambidae) (unpublished data); the wax extracts from MXPT1 and MXPT2, and the pure metabolites I, II, and III, only showed a moderate activity when tested using the same assay. These results do not coincide with those mentioned above and suggest that although it has been reported that a number of triterpenes present in cuticular waxes are associated with resistance to insect attack [18, 22], lupeolmethylether (I), skimmiwallin (II) and isoskimmiwallin (III) appear not to play a significant role in the palm-insect interaction. Alternatively, the antifeeding activity shown by the LYDresistant MYD wax extract, and the lack of antifeedant activity observed for the LYD-susceptible MXAT and MXPT3 wax ex-
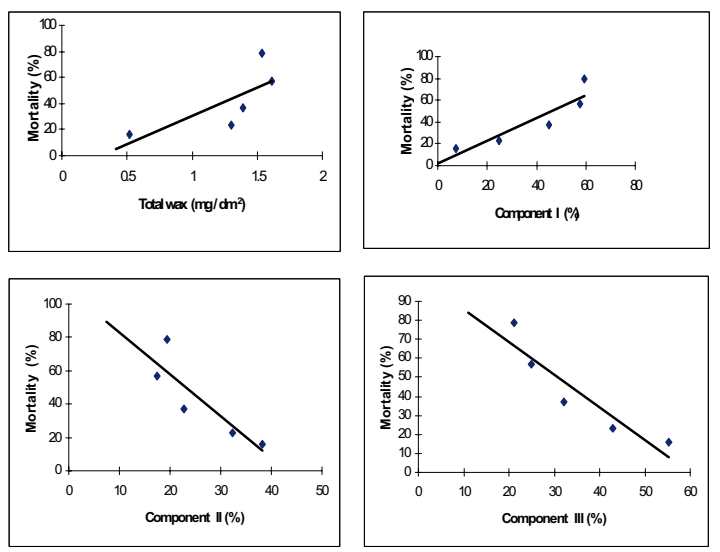

Fig. 5. Correlation between LDY-related mortality in C. nucifera and both, total wax content (a) and relative abundance of main components (b, c, and d). 
tracts, strongly suggests that the complete secondary metabolite composition of the cuticular wax is important for the resistance or susceptibility of a particular palm ecotype to LYD.

\section{Experimental}

Biological materials were collected in a coconut palm plantation kept by CICY in San Crisanto, Municipality of Sinanché, Yucatán, México. The area has a semiarid climate with a sandy soil, an annual rainfall of $670 \mathrm{~mm}$, and an average temperature of $26{ }^{\circ} \mathrm{C}$. For this study, plants growing in similar environmental conditions, and with healthy and vigorous vegetative development, were selected. The collection of pinnae from coconut palms was carried out on April 19, 1999.

One-month old pinnae (five pinnae per individual; ten individuals of each ecotype) were first dusted with tissue paper and folded to bring together the base and the tip of the pinna, cutting the excess of material so that the folded pinna had a length of $26 \mathrm{~cm}$. Folded pinnae were dipped for $40 \mathrm{sec}$ in 250 $\mathrm{ml}$ of hexane contained in a measuring cylinder, being careful not to submerge the cut off ends. The solvent was evaporated under reduced pressure and the wax residue was transferred to a vial using dichloromethane; the solvent was eliminated using a flow of nitrogen and the vials were placed in a dessicator under high vacuum, until they reached constant weight.

After extraction, the adaxial surface of each pine was photocopied and the foliar area was calculated using an image-digitalizer connected to a computer which integrated and registered the values using the Agimagen ${ }^{\circledR}$ program. The yield of cuticular wax was calculated by dividing the amount of wax between the foliar area.

Gas Chromatography analyses of cuticular wax extracts (1\%) were carried out in triplicate, using a Hewlett Packard 5890 Gas Chromatographer equipped with an Ultra 1 column $(25 \mathrm{~m} \times 0.2 \mathrm{~mm}$ ), a flow rate (Nitrogen) of $1 \mathrm{~mL} / \mathrm{min}$, and a temperature program of $\mathrm{T}_{1}=280{ }^{\circ} \mathrm{C}(2 \mathrm{~min}), \mathrm{T}_{2}=300{ }^{\circ} \mathrm{C}(5$ $\min )$, gradient $=5{ }^{\circ} \mathrm{C} / \mathrm{min}$. Wax extracts were not subjected to pre-purification nor derivatization prior to their GC analyses.

Statistical analyses were carried out using the Statistical Analysis System software Release 6.12 [28]. The classification study (Fig. 4) was performed using an agglomerative hierarchical cluster analysis, using a CLUSTER procedure to examine the clustering pattern of the various ecotypes. The analyses were carried out on the basis of each ecotype's matrix of means; the elements of the matrix were standardized to mean 0 and standard deviation 1, and from this the matrix of similarities of the Euclidean distance. Clustering was done by using the un-weighted pair group method with arithmetic averages (UPGMA). The resulting tree is not rooted. The differences in total wax content (Fig. 1 and Table 1), and the differences in the relative amount of each component in the cuticular wax of the various ecotypes (Fig. 3 and Table 1), were established by means of a series of one-way analyses of variance (ANOVA) and comparison of means through Tukey's test $(P>0.05)$. The correlation between cuticular wax composition and susceptibil-
Table 1. Mean and standard error (SE) of total wax content (A) and relative abundance of lupeol-methylether (I), skimmiwallin (II) and isoskimmiwallin (III) in cuticular wax of Cocos nucifera ecotypes.

\begin{tabular}{ccccccccc}
\hline & \multicolumn{2}{c}{ A } & \multicolumn{2}{c}{ I } & \multicolumn{2}{c}{ II } & \multicolumn{2}{c}{ III } \\
\hline Ecotype $^{1}$ & Mean & SE & Mean & ES & Mean & ES & Mean & ES \\
MXAT & 1.57 & 0.11 & 59.2 & 2.9 & 21.5 & 2.6 & 19.3 & 1.2 \\
MXPT1 & 1.34 & 0.1 & 42.7 & 7.4 & 33.6 & 5 & 23.7 & 2.3 \\
MXPT2 & 1.15 & 0.07 & 16.1 & 5.1 & 47.2 & 3.1 & 36.7 & 2.1 \\
MXPT3 & 1.52 & 0.17 & 55.5 & 4.1 & 26 & 2.3 & 18.5 & 1.8 \\
MYD & 0.52 & 0.04 & 6.6 & 0.22 & 55.3 & 0.7 & 38.2 & 0.6 \\
\hline
\end{tabular}

ity to LYD (Fig. 5) was established using the linear regression equation: $Y=a+b X$.

\section{Acknowledgements}

The authors wish to thank Miguel Fernández for helping to collect the plant material and both Anne E. Osbourn and Reinhard Jetter for their valuable comments on reviewing the manuscript.

\section{References}

1. Taufikkurahman, L. Coconut Statistical Yearbook. Asian and $\mathrm{Pa}$ cific Community. 2. 1993.

2. Zizumbo-Villarreal, D.; Been, B.; Tupinanmba, E.; Castillo, R.; Oropeza, C., in: Status of coconut genetic resources, Batugal, P.; Rao, R.; Oliver, J. (eds), COGENT-IPGRI-APO, Serdang, Malaysia, 2005, 573-580.

3. Howard, F.W. World. FAO Plant Bull. Protect. 1983, 34, 101103.

4. Oropeza, C.; Escamilla, J.; Mora, G.; Zizumbo, D.; Harrison, N., in: Status of coconut genetic resources, Batugal, P.; Rao, P.; Oliver, J. (eds.), COGENT-IPGRI-APO, Serdang, Malaysia, 2005, 449-463.

5. Zizumbo-Villarreal, D.; Hernández, F.; Harries, H. C. Econ. Bot. 1993, 47, 65-78.

6. Zizumbo-Villarreal, D.; Ruiz-Rodriguez, M.; Harries, H.; Colunga-Garcíamarín P. Crop Sci. 2006, 46, 2509-2516.

7. Zizumbo-Villarreal, D.; Fernández, M.; Torres, N.; Cardeña, R., in: Current Plant Science in Biotechnology and Agriculture, Oropeza, C.; Verdell, J. L.; Asburner, G. R.; Cardeña, R.; Santamaría, J. M. (eds), Kluwer Academic Publishers, 1999, 131-159.

8. Szafranek, B.; Tomaszewski, D.; Pokrzywinska, K.; Golebiowski, M. Acta Biol. Cracov., Series Botanica 2008, 50, 49-54.

9. Buschhaus, C.; Herz, H.; Jetter, R. Ann. Bot. 2007, 100, $1557-$ 1564.

10. Haas, K.; Bauer, M.; Wollenweber, E. Z. Naturforsch. 2003, 58c, 464-470.

11. Riedel, M.; Eichner, A.; Jetter, R. Planta 2003, 218, 87-97.

12. Teusink, R. S.; Rahman, M.; Bressan, R. A.; Jenks, M. A. Int. J. Plant Sci. 2002, 163, 309-315.

13. Fröhlich, B.; Riederer, M.; Tautz, J. Apidologie 2001, 32, 1-10.

14. Fröhlich, B.; Tautz, J.; Riederer, M. J. Chem. Ecol. 2000, 26, 123137.

15. Jetter, R.; Schäffer, S.; Riederer, M. Plant Cell Environ. 2000, 23, 619-628. 
16. Shepherd, T.; Robertson, G. W.; Griffiths, D. W.; Birch, A. N. E. Phytochemistry 1999, 52, 1255-1267.

17. Berenbaum, M. R.; Zangerl, A. R. Proc. Natl. Acad. Sci. USA 1998, 95, 13743-13748.

18. Eigenbrode, S. D.; Pillai, S. K. J. Chem. Ecol. 1998, 24, 16111627.

19. Rhee, Y.; Hlousek-Radojcic, A.; Ponsamuel, J.; Liu, D.; Post-Beittenmiller, D. Plant Physiol. 1998, 116, 901-911.

20. Rashotte, A. M.; Jenks, M. A.; Nguyen, T. D.; Feldmann, K. A. Phytochemistry 1997, 45, 251-255.

21. Berenbaum, M. R. Proc. Natl. Acad. Sci., USA 1995, 92, 2-8.

22. García, S.; Heinzen, H.; Hubbuch, C.; Martínez, R.; De Vries, X.; Moyna, P. Phytochemistry 1995, 39, 1381-1382.
23. Manners, G. D.; Davis, D. G. Phytochemistry 1984, 23, 1059-1062.

24. Escalante-Erosa, F.; Gamboa-León, M. R.; Lecher, J. G.; ArroyoSerralta, G. A.; Zizumbo-Villareal, D.; Oropeza-Salín, C.; PeñaRodríguez L. M. Rev. Soc. Quím. Méx., 2002, 46, 247-250.

25. Kurup, V. V. G. K.; Voleti, S. R.; Rajagopal, V. J. Plant. Crops 1993, 21, 71-80.

26. Riedel, M.; Riederer, M.; Becker, D.; Herran, A.; Kullaya, A.; Arana-López, G.; Peña-Rodríguez, L.M.; Billote, N.; Sniady, V.; Ritter, E.; Rohde, W. Tree Genet. Genom. 2009, 5, 53-69.

27. Escalante-Erosa, F.; Arvízu-Méndez, G. E.; Peña-Rodríguez, L. M. Phytochem. Anal. 2007, 18, 188-192.

28. SAS, SAS/STAT User's guide, release 6.12 edition. SAS Institute Inc., Cary, NC. 1997. 